\title{
Variations in factors associated with healthcare providers' intention to engage in interprofessional shared decision making in home care: results of two cross-sectional surveys
}

Rhéda Adekpedjou', Julie Haesebaert ${ }^{2}$, Dawn Stacey ${ }^{3}$, Nathalie Brière ${ }^{4}$, Adriana Freitas ${ }^{1}$, Louis-Paul Rivest ${ }^{5}$ and France Légaré ${ }^{1,6^{*}}$ (D)

\begin{abstract}
Background: DOLCE (Improving Decision making On Location of Care with the frail Elderly and their caregivers) was a post-intervention clustered randomised trial (CRT) to assess the effect of training home care teams on interprofessional shared decision-making (IP-SDM). Alongside the CRT, we sought to monitor healthcare providers' level of behavioural intention to engage in an IP-SDM approach and to identify factors associated with this intention.

Methods: We conducted two cross-sectional surveys in the province of Quebec, Canada, one each at cRT entry and exit. Healthcare providers (e.g. nurses, occupational therapists and social workers) in the 16 participating intervention and control sites self-completed an identical paper-based questionnaire at entry and exit. Informed by the Integrated model for explaining healthcare professionals' clinical behaviour by Godin et al. (2008), we assessed their behavioural intention to engage in IP-SDM to support older adults and caregivers of older adults with cognitive impairment to make health-related housing decisions. We also assessed psychosocial variables underlying their behavioural intention and collected sociodemographic data. We used descriptive statistics and linear mixed models to account for clustering.

* Correspondence: France.Legare@mfa.ulaval.ca

${ }^{1}$ Centre de recherche sur les soins et les services de première ligne de I'Université Laval, Quebec, Canada

${ }^{6}$ Canada Research Chair in Shared Decision Making and Knowledge Translation, 2525, chemin de la Canardière, Quebec G1J 0A4, Canada

Full list of author information is available at the end of the article

C The Author(s). 2020 Open Access This article is licensed under a Creative Commons Attribution 4.0 International License, which permits use, sharing, adaptation, distribution and reproduction in any medium or format, as long as you give appropriate credit to the original author(s) and the source, provide a link to the Creative Commons licence, and indicate if changes were made. The images or other third party material in this article are included in the article's Creative Commons licence, unless indicated otherwise in a credit line to the material. If material is not included in the article's Creative Commons licence and your intended use is not permitted by statutory regulation or exceeds the permitted use, you will need to obtain permission directly from the copyright holder. To view a copy of this licence, visit http://creativecommons.org/licenses/by/4.0/. The Creative Commons Public Domain Dedication waiver (http://creativecommons.org/publicdomain/zero/1.0/) applies to the data made available in this article, unless otherwise stated in a credit line to the data. 
(Continued from previous page)

Results: Between 2014 and 2016, 271 healthcare providers participated at study entry and 171 at exit. At entry, median intention level was 6 in a range of 1 (low) to 7 (high) (Interquartile range (IQR): 5-6.5) and factors associated with intention were social influence $(\beta=0.27, P<0.0001)$, beliefs about one's capabilities $(\beta=0.43$, $P<0.0001)$, moral norm $(\beta=0.31, P<0.0001)$ and beliefs about consequences $(\beta=0.21, P<0.0001)$. At exit, median intention level was 5.5 (IQR: 4.5-6.5). Factors associated with intention were the same but did not include moral norm. However, at exit new factors were kept in the model: working in rehabilitation $(\beta=-0.39, P=0.018)$ and working as a technician ( $\beta=-0.41, P=0.069)$ (compared to as a social worker).

Conclusion: Intention levels were high but decreased from entry to exit. Factors associated with intention also changed from study entry to study exit. These findings may be explained by the major restructuring of the health and social care system that took place during the 2 years of the study, leading to rapid staff turnover and organisational disturbance in home care teams. Future research should give more attention to contextual factors and design implementation interventions to withstand the disruption of system- and organisational-level disturbances.

Trial registration: Clinicaltrials.gov (NCT02244359). Registered on September 19th, 2014.

Keywords: Interprofessional shared decision-making, Home care, Context, Implementation, Clustered randomised trial, Socio-cognitive theory

\section{Background}

When older adults lose autonomy and need more care, they face a decision about staying at home or moving into a nursing home. Although older adults with loss of autonomy should be the principal decision-makers about this choice, cognitive impairment may result in their caregivers making the decision instead [1]. Informal caregivers (eg. family members) play an essential role in caring for cognitively-impaired older adults [2]. However, studies show that they need more support in decision-making and more opportunity to participate in housing decisions made for their cognitively-impaired loved ones [3]. While caregivers are often the experts on the older adult's condition, history and care experiences $[4,5]$, they report negative experiences regarding this decision-making process, the choice, and the decision outcomes, possibly because of a lack of effective decision support $[1,6]$.

Home care enables a person to stay at home or return home quickly after an episode of care [7]. In 2015/2016, an estimated $3.3 \%$ of Canadians aged 18 or older $(919,000$ people) had received home care services in the past year, of whom 511,500 were over 65 years old [8]. For interprofessional home care teams caring for older adults with loss of autonomy, interprofessional shared decision-making (IP-SDM) is a promising way to approach decisionmaking about housing $[9,10]$. The IP-SDM model combines shared decision-making (SDM) [11] with interprofessional collaboration [12, 13]. From 2014 to 2016, we undertook a clustered randomised trial (cRT) of an IPSDM training program called the DOLCE study (Improving Decision-making On Location of Care with the frail Elderly and their caregivers). DOLCE assessed the effect of giving the training in 16 home care teams in the Province of Quebec on informal caregivers' participation in the health-related housing decisions of the older adults they cared for [14].

According to the results of the cRT [15], training the home care team in IP-SDM did seem to increase caregivers' participation in their loved ones' housing decisions [15]. We had hypothesised that this outcome would occur because post-training, the healthcare providers would involve caregivers more in the decisionmaking and give them more support. As we were also interested in the mechanisms behind this expected behaviour change in the healthcare providers, we used an integrated model of socio-cognitive variables to monitor the level of behavioural intention to engage in an IPSDM approach at cRT entry and exit and to identify factors associated with this intention [16].

\section{Theoretical background}

The medical community is increasingly aware of the SDM approach and SDM is now part of health policies in many countries [17]. Yet healthcare providers are slow to adopt it [18]. Behaviour change interventions are essential for improving the practice of clinical medicine, and a thorough understanding of the mechanisms underlying behaviour change is necessary for developing and improving SDM interventions $[19,20]$. Socio-cognitive theories provide validated constructs and measures for exploring the mechanisms that drive behaviour change [21].

Authors of a systematic review of socio-cognitive theories for studying healthcare providers' clinical behaviour [16] proposed an integrated model that combined the variables they found most important (Fig. 1). We chose this model because it was derived from an extensive systematic review of socio-cognitive theories that included 76 studies and also because it integrates validated 


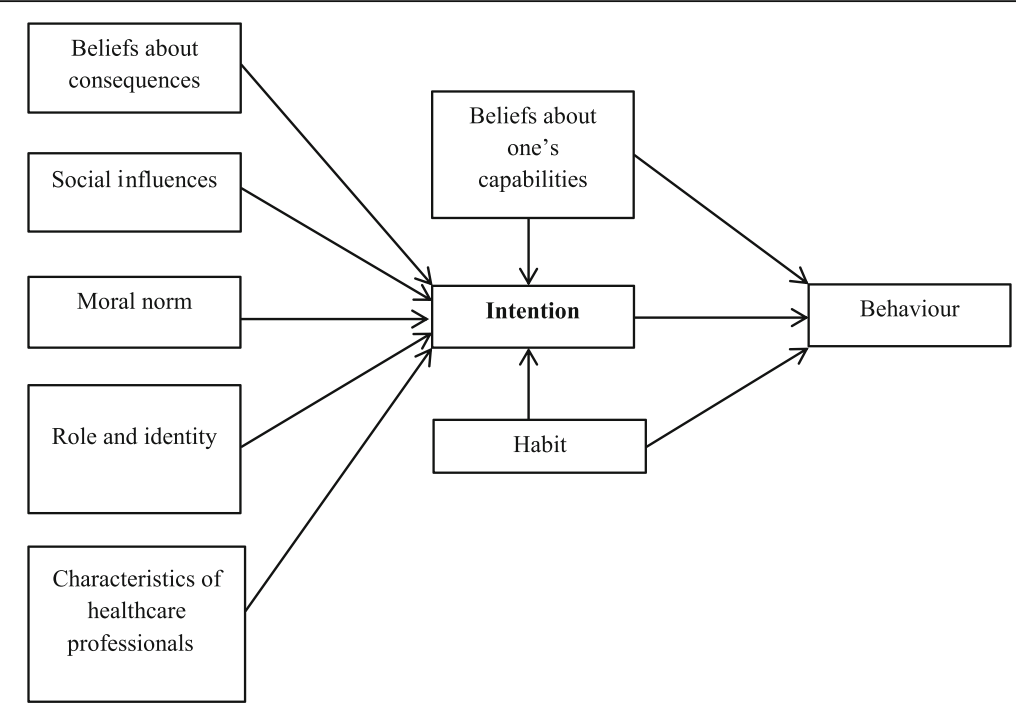

Fig. 1 Integrated model for explaining healthcare professionals' clinical behaviour

socio-cognitive theories with the highest overall efficacy for predicting intention such as the Theory of Planned Behaviour (59\% of the variance of intention was explained by the model) and the Triandis' Theory of Interpersonal Behaviour $(81 \%$ of the variance of intention was explained by the model). According to this model, the three most important psychosocial factors for predicting behaviour are habit or past behaviour, intention, and beliefs about one's capabilities (perceptions of facilitators and barriers to adopting the behaviour), with the latter two being most significant. The model also identifies the five most significant predictors of intention as beliefs about one's capabilities, beliefs about consequences (usefulness and benefits/risks of adopting the behaviour), moral norm (feeling of personal obligation to adopt the behaviour), social influences (perception of approval or disapproval by significant persons regarding adopting the behaviour), and role and identity (beliefs about whether the behaviour should be adopted by someone of a similar age, sex or social position as oneself).

We therefore measured healthcare providers' intention (and its theory-based predictors) to engage in an IPSDM approach. This study adheres to STROBE guidelines for reporting cross-sectional studies [22].

\section{Methods}

\section{Parent study design}

Between April 2014 and August 2016, we conducted a two-arm cluster randomised trial with interprofessional home care teams in 16 health and social services centres (HSSCs) in seven health jurisdictions in the province of Quebec, Canada. Details of the study protocol can be found elsewhere [14]. Briefly, study participants were the HSSCs, their interprofessional home care teams, and caregivers of their elderly clients with loss of autonomy and cognitive impairment. The intervention consisted of training in the IP-SDM approach (an online tutorial and a live interactive workshop) and in use of a decision guide. The primary outcome was caregivers' self-reported role in decision-making. At the entry into the study and after obtaining informed consent, a self-administered questionnaire was given to each member of the interprofessional home care team of the 16 HSSCs to measure their intention (and its determinants) to adopt an SDM approach. Healthcare providers in the HSSCs allocated to the intervention group participated in the training but not those in the control group. The same questionnaire was given again to all participants (both the intervention and control groups) at study exit. This paper reports on data collected during these two cross-sectional surveys at study entry and exit. As the parent trial showed no difference in intention pre-post intervention between the control group and the intervention group (and this trial was neither designed nor powered for that), we chose to consider the data as two separate cross-sectional surveys (alongside the trial), rather than as pre-post intervention data. We took this approach to capture how external factors may have affected the intention to engage in IP-SDM (and its theory-based predictors) over time.

\section{Setting and participants}

Eligible interprofessional home care teams a) were involved in caring for older adults with loss of autonomy, and b) practised in one of the participating HSSCs. A minimum of two healthcare providers from different professions had to be involved in the older adult's care (definition of an interprofessional approach). Only one interprofessional home care team per HSSC was invited 
to participate. The selection of the teams was done by home care managers. The way teams were selected varied from one setting to another. The teams were chosen for different reasons: the stability of the team, the number of clients served per week (to be able to recruit the required number of clients in the trial), the budget allocated for the team to participate in the study (for the time spent in the IP-SDM training and the time spent in recruiting clients), and the fact that the team had not participated in the pilot version of the study. There was no financial compensation for the participants.

\section{Data collection and variables}

Data collection took place before the trial in February 2015 and after the trial in October 2016. Data was collected anonymously from healthcare providers using a paper-based self-reported questionnaire: the CPDReaction Questionnaire [23]. This validated instrument [23, 24] followed a strict development procedure [23]. It assesses the impact of training on clinical behavioural intention using items based on our socio-cognitive model [16]. The first section defines the targeted behaviour, i.e. engaging in IP-SDM with elderly home care clients and their caregivers who will be facing a healthrelated housing decision in the next 6 months. The second assesses five constructs: intention (two items), beliefs about one's capabilities (three items), beliefs about consequences (two items), social influence (three items) and moral norm (two items). Scores per construct range from 1 (low) to 7 (high) (see Additional file 1 for more details). "Habit" and "role and identity" were missing from the variables because they are not assessed by the CPD-Reaction Questionnaire. During its development, items concerning "habit" were removed because they were poorly worded and did not reflect our integrated model's definition of "habit". Items concerning "role and identity" were also removed because none of them loaded on any factors as defined by exploratory factor analysis [23]. The Cronbach's alpha coefficient in entry and exit questionnaires was 0.77 and 0.86 respectively for intention, 0.73 and 0.77 for social influence, 0.79 and 0.86 for beliefs about capabilities, 0.74 and 0.61 for moral norm, and 0.83 and 0.86 for beliefs about consequences. The third section collects sociodemographic characteristics: date of birth, sex, mean number of clients served per week and profession. Possible professions were social worker, nurse, occupational therapist, physiotherapist, physician and other (specified). The dependent variable was the healthcare professionals' intention to engage in IP-SDM. Our independent variables were beliefs about one's capabilities, beliefs about consequences, social influence, moral norm and sociodemographic characteristics.

\section{Statistical analysis}

We used descriptive statistics to describe the level of the intention to engage in IP-SDM and the four other psychosocial constructs at study entry and study exit and to describe sociodemographic characteristics of healthcare providers. For profession, the response category "other" contained several types of profession that were not classifiable in the five other response categories. We therefore created a new variable using the National Occupational Classification (NOC) of Canada [25] to achieve more homogenous professional groups: 1) nurses, 2) rehabilitation team (e.g. physiotherapist, occupational therapist), 3) technicians (e.g. licensed practical nurse, respiratory therapist), 4) social workers, 5) social, community and education paraprofessionals (e.g. community worker, special education technician), and 6) activities coordinators.

For most of the pre-trial and post-trial variables, the proportion of missing data ranged from $0.58 \%$ to $1.11 \%$. For the variable "number of clients per week", the proportion of missing data was $6.64 \%$ pre-trial and $5.26 \%$ posttrial. We compared the characteristics of the participants who provided data for this variable with the characteristics of those who did not and they appeared to be similar. Missing values for that variable seemed to be missing completely at random (MCAR). For these reasons and given the low level of missing data for all variables, we considered that pairwise deletion would be appropriate to address missing data.

To take the non-independence of the data into account (clustering effect), we used multilevel modelling (linear mixed model). This was done by specifying a random effect at the HSSC level. To identify factors associated with healthcare providers' intention to engage in IP-SDM at study entry, we first performed bivariate analyses to examine the relationship between the theory-based factors and the intention score (at 0.20 alpha level) [26]. Following bivariate analyses, we performed multilevel multivariate regression analysis using backward elimination for model selection. We used the same approach to identify factors associated with healthcare providers' intention to engage in IP-SDM at study exit. We computed a study entry model and a study exit model. In the study entry model, intention at entry was regressed on variables measured before the trial. In the study exit model, intention at exit was regressed on variables measured after the trial and on the variable representing the study groups (intervention vs. control). For profession, activities coordinators were not considered in the regression analyses given the weak number of participants $(n=2)$. Due to the exploratory nature of the analysis, a $p$-value of $<0.10$ was used as the threshold for statistical significance in the final models [27, 28].

We conducted model diagnostics by assessing multicollinearity, distribution of scaled residuals, homoscedasticity, and influential observations. 
We performed the analysis using SAS version 9.4 (SAS Institute Inc., Cary, NC, USA) with the MIXED procedure.

\section{Ethical issues and parent study registration}

Ethics committee review approval was obtained from the Centre Hospitalier Universitaire (CHU) de Québec Multicentre Ethics Committee (approval number MP-CHUQC-14-001). All participants gave written informed consent. The parent study is registered at clinicaltrials.gov (registration number: NCT02244359).

\section{Results}

Flow of the trial and characteristics of participants

Sixteen HSSCs participated in the study. Totals of 271 and 171 healthcare providers completed the questionnaire at entry and exit respectively (Fig. 2). Participants' sociodemographic characteristics are reported in Table 1. In both samples, most of the healthcare providers were female (90.4\% at entry and $88.9 \%$ at exit) with a median age of 36.1 years (Interquartile range (IQR): 30.1-45.9) in the entry sample and 38.6 years (IQR: 31.9-48.1) in the exit sample. Additional file 2 provides scores of the five

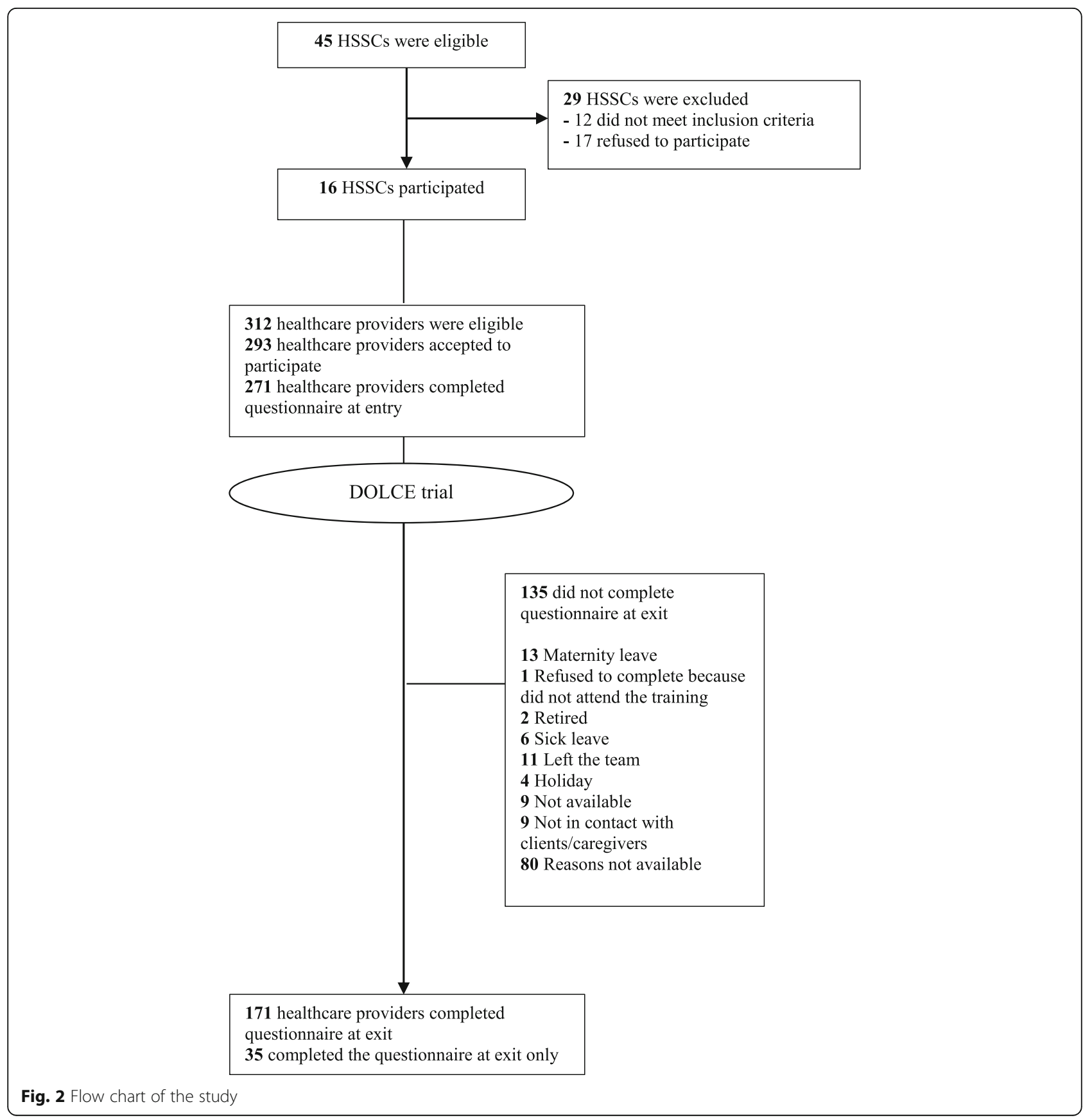


Table 1 Characteristics of the participants at study entry and study exit (both intervention and control groups)

\begin{tabular}{|c|c|c|}
\hline Characteristics & At study entry (n 271) & At study exit $(n=171)$ \\
\hline & Number (percentage) & \\
\hline \multicolumn{3}{|l|}{ Sex } \\
\hline Male & $26(9.6)$ & $18(10.5)$ \\
\hline Female & $245(90.4)$ & $152(88.9)$ \\
\hline Missing & $0(0)$ & $1(0.6)$ \\
\hline \multicolumn{3}{|l|}{ Profession } \\
\hline Nurses & $61(22.5)$ & $29(16.9)$ \\
\hline Rehabilitation team & $50(18.5)$ & $34(19.9)$ \\
\hline Technicians & $10(3.7)$ & $7(4.1)$ \\
\hline Social workers & $100(36.9)$ & $75(43.8)$ \\
\hline Social, community \& education paraprofessionals & $48(17.7)$ & $23(13.5)$ \\
\hline Activities coordinators & $2(0.7)$ & $2(1.2)$ \\
\hline \multirow[t]{2}{*}{ Missing } & $0(0)$ & $1(0.6)$ \\
\hline & \multicolumn{2}{|l|}{ Median (interquartile range) } \\
\hline Age (in years) & $36.1(30.1-45.9)$ & $38.6(31.9-48.1)$ \\
\hline Number of clients served per week & $15(10-25)$ & $15(10-20)$ \\
\hline Intention & $6(5-6.5)$ & $5.5(4.5-6.5)$ \\
\hline Social influence & $5.5(5.1-6.2)$ & $5.5(4.7-6.2)$ \\
\hline Beliefs about capabilities & $5.7(5-6.3)$ & $5.7(5-6.3)$ \\
\hline Moral norm & $6.3(5.5-7)$ & $6.2(5.5-7)$ \\
\hline Beliefs about consequences & $6(5.5-7)$ & $6(5-6.5)$ \\
\hline
\end{tabular}

determinants according to profession. Technicians and activities coordinators reported the lowest levels of intention at study entry and these scores decreased at study exit.

\section{Healthcare providers' intention to engage in IP-SDM at} study entry and factors associated with intention

Healthcare providers' scores of intention to engage in IPSDM at entry was 6 in a range of 1 (low) - 7 (high) (IQR: 5-6.5). In multilevel multivariate regression analyses (Table 2), the factors associated with higher healthcare providers' intention to engage in IP-SDM were perception of approval by colleagues or significant others in the profession ("social influence") $(\beta=0.27, P<0.0001)$, perceptions of facilitators and barriers to adopting the behavior ("beliefs about their capabilities") $(\beta=0.43, P<0.0001)$, feeling of personal obligation to engage in IP-SDM ("moral norm") ( $\beta=0.31, P<0.0001)$ and beliefs about the usefulness and the benefits of engaging in it ("beliefs about consequences") $(\beta=0.22, P<0.0001)$. These factors explained $68.4 \%$ of the variance of the intention in the model $\left(R^{2}\right)$.

\section{Healthcare providers' intention to engage in IP-SDM at} study exit and factors associated with intention

Healthcare providers' score of intention to engage in IPSDM at exit was 5.5 (IQR: 4.5-6.5). In multilevel multivariate regression analyses (Table 3), the same factors were associated with higher intention to engage in IPSDM except for moral norm (feeling of personal obligation to adopt the behaviour). However, unlike at study entry, new factors were kept in the final model: working in a rehabilitation team $(\beta=-0.39, P=0.018)$ or as a technician $(\beta=-0.41, p=0.069)$. The associated factors explained $77.1 \%$ of the variance of the intention in the model $\left(R^{2}\right)$.

\section{Discussion}

Alongside a clustered randomised trial of an IP-SDM intervention, we monitored healthcare providers' level of intention to engage in IP-SDM in home care and identified factors associated with intention. Intention levels were high but decreased from entry to exit. At trial entry, we observed that greater social influence, beliefs about capabilities, moral norm, and beliefs about consequences were associated with greater intention to engage in IP-SDM. At exit, the same factors were observed with the exception of moral norm. In addition, we observed that working in rehabilitation or as a technician (compared to working as a social worker) were associated with lower intention. This led us to make the following observations. 
Table 2 Factors associated with healthcare professionals' intention to use the IP-SDM at study entry $(n=269)^{a}$

\begin{tabular}{|c|c|c|c|c|c|c|}
\hline \multirow[t]{2}{*}{ Variables } & \multicolumn{3}{|c|}{ Bivariate analyses $^{\mathrm{b}}$} & \multicolumn{3}{|c|}{ Final model ${ }^{b}$} \\
\hline & $\bar{\beta}$ & $95 \% \mathrm{Cl}$ & $p$-value ${ }^{a}$ & $\bar{\beta}$ & $95 \% \mathrm{Cl}$ & $p$-value ${ }^{\#}$ \\
\hline Age (in years) & -0.014 & -0.030 to 0.000 & 0.060 & - & - & - \\
\hline \multicolumn{7}{|l|}{ Sex } \\
\hline Female (vs male) & 0.87 & 0.31 to 1.42 & 0.004 & & & \\
\hline Number of clients served per week & -0.014 & -0.026 to -0.001 & 0.027 & - & - & - \\
\hline Profession & & & 0.223 & & & \\
\hline Nurses (vs Social workers) & -0.29 & -0.72 to 0.14 & 0.183 & - & - & - \\
\hline Rehabilitation team (vs Social workers) & -0.17 & -0.63 to 0.28 & 0.451 & - & - & - \\
\hline Technicians (vs Social workers) & -1.10 & -1.94 to -0.24 & 0.013 & - & - & - \\
\hline Social, community \& education paraprofessionals (vs Social workers) & -0.18 & -0.66 to 0.29 & 0.445 & - & - & - \\
\hline Social influence & 0.87 & 0.75 to 0.98 & $<0.0001$ & 0.27 & 0.14 to 0.39 & $<0.0001$ \\
\hline Beliefs about capabilities & 0.93 & 0.83 to 1.03 & $<0.0001$ & 0.43 & 0.31 to 0.56 & $<0.0001$ \\
\hline Moral norm & 0.94 & 0.84 to 1.05 & $<0.0001$ & 0.31 & 0.17 to 0.45 & $<0.0001$ \\
\hline Beliefs about consequences & 0.82 & 0.71 to 0.93 & $<0.0001$ & 0.21 & 0.10 to 0.33 & $<0.001$ \\
\hline$R^{2}$ & & & & $68.4^{\circ}$ & & \\
\hline
\end{tabular}

${ }^{a}$ Activities coordinators were not considered in the analyses given the small number of participants $(n=2)$

${ }^{\mathrm{b}}$ Linear mixed regression model with adjustment for clustering

${ }^{a}$ At 0.20 alpha level

\# A $p$-value of $<0.10$ was used as the threshold for statistical significance in the final models

"_" This variable was not kept in the final model

First, regarding factors associated with intention, our results are supported by a large body of accumulated evidence. A systematic review of healthcare providers' intention to use research and products of research in clinical practice reported that attitude, subjective norm and perceived behavioural control (three predictors of intention according to the Theory of Planned Behaviour [29]) were dominant predictors of intention in a range of behaviours [30]. These predictors correspond to beliefs about consequences, social influence and beliefs about capabilities in our integrated model. Another systematic review reported that the same three theorybased variables were most often identified as determinants of healthcare providers' intention to engage in SDM-related behaviours [31]. Our results suggest that moral norm should be added as another important factor associated with intention to engage in IP-SDM, a result supported by literature relating to a number of different behaviours such as to use a decision aid for Down Syndrome screening in the context of prenatal consultation with a pregnant woman and her partner, to engage preschoolers in physical activity in the context of childcare, and to practice euthanasia for end-of-life patients in the context of palliative care [16, 32-39], especially concerning behaviours with an ethical dimension [35]. This is coherent with increasing recognition that SDM should be considered not just as a pragmatic approach but as an ethical imperative [40]. As stated by
Elwyn and colleagues, "the imperative for shared decision-making rests on the principles of good clinical practice, respecting patients' right to know that their informed preferences should be the basis for healthcare providers' actions" [41]. In a study of the psychosocial determinants of physicians' intention to practice euthanasia in palliative care, researchers measured three ethical principles underlying moral norm: autonomy (e.g. believing patients should control when they die), beneficence (e.g. believing euthanasia will provide them relief) and justice (e.g. believing that euthanasia frees resources for others in need) [37]. They found that moral norm in the case of the physicians was related to beneficence. In the case of SDM, it would be interesting to study how autonomy (e.g. believing patients should have more control over their own healthcare decisions), beneficence (e.g. believing that involving patients in decisions about their health care is associated with less decision regret afterwards) or justice (e.g. believing that informed patients will choose less costly options and free up resources for others), are related to moral norm among healthcare providers considering whether to engage in IP-SDM. This knowledge could inform the design of interventions designed to target moral norm.

Second, at study exit, intention scores decreased, moral norm was no longer associated with intention, and additional factors appeared. As at study entry, intention still increased when social influence, beliefs 
Table 3 Factors associated with healthcare professionals' intention to engage in IP-SDM at study exit $(n=169)^{a}$

\begin{tabular}{|c|c|c|c|c|c|c|}
\hline \multirow[t]{2}{*}{ Variables } & \multicolumn{3}{|c|}{ Bivariate analyses $^{\mathrm{b}}$} & \multicolumn{3}{|c|}{ Final model $^{\mathrm{b}}$} \\
\hline & $\bar{\beta}$ & $95 \% \mathrm{Cl}$ & $p$-value ${ }^{a}$ & $\bar{\beta}$ & $95 \% \mathrm{Cl}$ & $p$-value ${ }^{\#}$ \\
\hline Age (in years) & -0.001 & -0.025 to 0.022 & 0.929 & - & - & - \\
\hline \multicolumn{7}{|l|}{ Sex } \\
\hline Female (vs male) & 0.21 & -0.65 to 1.08 & 0.597 & - & - & - \\
\hline Number of clients served per week & -0.022 & -0.040 to -0.004 & 0.015 & - & - & - \\
\hline Profession & & & $0.036^{d}$ & & & 0.001 \\
\hline Nurses (vs Social workers) & -0.00 & -0.68 to 0.66 & 0.982 & 0.02 & -0.25 to 0.29 & 0.888 \\
\hline Rehabilitation team (vs Social workers) & -0.36 & -1.00 to 0.28 & 0.257 & -0.39 & -0.72 to -0.07 & 0.018 \\
\hline Technicians (vs Social workers) & -1.78 & -2.99 to -0.58 & 0.005 & -0.41 & -0.86 to 0.03 & 0.069 \\
\hline Social, community \& education paraprofessionals (vs Social workers) & 0.21 & -0.51 to 0.95 & 0.547 & -0.06 & -0.48 to 0.35 & 0.760 \\
\hline Social influence & 0.99 & 0.86 to 1.11 & $<0.0001$ & 0.34 & 0.22 to 0.46 & $<0.0001$ \\
\hline Beliefs about capabilities & 0.99 & 0.88 to 1.09 & $<0.0001$ & 0.46 & 0.25 to 0.68 & $<0.0001$ \\
\hline Moral norm & 0.87 & 0.68 to 1.07 & $<0.0001$ & - & - & - \\
\hline Beliefs about consequences & 1.08 & 0.95 to 1.21 & $<0.0001$ & 0.42 & 0.21 to 0.63 & $<0.001$ \\
\hline \multicolumn{7}{|l|}{ Intervention } \\
\hline Intervention (vs no intervention) & -0.30 & -0.98 to 0.38 & 0.355 & - & - & - \\
\hline$R^{2}$ & & & & $77.1 \%$ & & \\
\hline
\end{tabular}

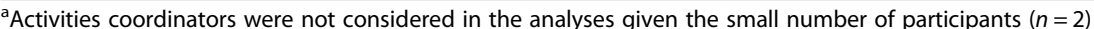

${ }^{\mathrm{b}}$ Linear mixed regression model with adjustment for clustering

${ }^{\text {aAt }} 0.20$ alpha level

${ }^{\mathrm{d} O v e r a l l ~} p$-value

"-" This variable was not kept in the final model

\# A $p$-value of $<0.10$ was used as the threshold for statistical significance in the final models

about one's capabilities and beliefs about consequences increased. But working in the rehabilitation team or as a technician tended to lower intention compared to being a social worker. We also observed that the intention of activities coordinators decreased at exit. As shown by the results, the intervention had no effect on intention. Moreover, the evaluation of the workshop showed that the satisfaction of the healthcare providers who followed the training was high (results not shown). Therefore, the decrease in the level of intention cannot be explained by the implementation of the intervention. This variation in level of intention among team members and in the factors associated with their intention may be explained by staff workload, staff turnover and discouragement caused by major changes in the health and social care system that occurred during the course of the study (20142015), when the Province of Quebec entirely restructured its health and social care system [42], requiring many providers to take on extra clients. Indeed, as a result of the restructuring, 1394 workers lost their jobs and home care providers experienced a $36.9 \%$ increase in patient interventions (2014-2017) [43]. According to our data, rehabilitation workers and technicians were the professional groups that reported an increase in the median number of clients served per week from study entry to study exit (results not shown). Staff workload has been identified as barrier to engaging in IP-SDM [44] and the related lack of time is the most widely reported barrier, as indeed for uptake of many innovations [45]. These upheavals also resulted in high staff turnover, which deeply affected the home care teams who participated in the study. Several participants left the teams, did not complete the questionnaire at exit, and gave no reasons. High staff turnover is frequently identified by healthcare providers as a barrier to engaging in IP-SDM [44]. This factor affects team cohesion and communication and is likely to directly impact the quality of the provider-patient relationship, as well as the relationships among providers [46]. All these organisational disturbances may explain the observed activities coordinators' lower intention to engage in IPSDM at exit.

Third, the discouragement experienced by staff as a result of these upheavals may also explain why moral norm did not appear to be a factor associated with intention at exit. Even if healthcare providers still found it acceptable and ethical to engage in IP-SDM, their intention was no longer driven by what they considered morally acceptable or desirable but by practical issues that may have hindered successful interprofessional 
collaboration. A systematic review of reviews has shown that systemic upheavals can undermine commonly held values or beliefs in a society at a given time, such as evidence-based practice and patient-centred care. Authors highlight the importance of aligning interventions with system characteristics (e.g. policy and legislation, local and national agenda), organizational characteristics (e.g. leadership, organisational readiness, existing workflow, clarity of roles and responsibilities, and division of labour) as well as professional characteristics (e.g. attitudes to change, perception of time and workload) [47]. Indeed most SDM research has focused more on strategies that address professional-level barriers [48] and less on identifying and assessing strategies that address barriers at the organisational and system levels [49]. Organisational contexts needs to be seen as an integral part of behaviour change instead of a source of confounding variables [50] in order to explore how implementation interventions can be designed to withstand the disruptions of system level and organisational level disturbances.

This study has a number of limitations. First, it was embedded in a larger study and was neither designed nor powered for our stated objectives. Second, there were few respondents in some of the provider categories (e.g. technicians and activities coordinators). A bigger sample size would have given us more confidence in the interpretation of our results regarding these groups. Third, it is possible that a social desirability bias occurred because of the increasing popularity of and public pressure for patient involvement in health-related decisions [17], as suggested by the overall high scores of intention and its determinants. Fourth, we collected data at the individual level only. Gathering data at other levels of context (system and organisation) would have had given us deeper insight into how the health and social care reforms influenced the healthcare providers' level of intention and its associated factors. Fifth, we did not have observational data to assess how these levels of intention to engage in IP-SDM translate into healthcare providers' adoption of that behaviour. Another limitation is related to the exploratory nature of the analysis. Our analytical approach may have overestimated the measures of association and may have produced false positive tests. However, this approach was not only based on the data, since variables collected were informed by validated socio-cognitive theories. In addition, even if little is known about factors associated with healthcare providers' intention to engage in IP-SDM, our results are consistent with other evidence on determinants of healthcare providers' intention to engage in healthrelated behaviours [16, 29-31]. Finally, more than 100 of the participants who completed the questionnaire at entry did not complete the questionnaire at exit.
Completion of the questionnaire at exit by these participants would have given us a larger sample size and a more complete picture of the level of intention at exit and its associated factors. Despite this, the possibility of non-response bias is very low for the following reasons: most non-respondents did not complete the questionnaire at exit because they were on leave, had left the team or lost their jobs, i.e. their non-response was unrelated to their intention to engage in IP-SDM. Second, removing those who did not complete the questionnaire at exit from the entry dataset does not change the results of the analysis, i.e. those who completed the questionnaire at both entry and exit did not differ in meaningful ways from those who did not complete it at exit.

\section{Implications for research}

These findings have several implications for future research. First, as SDM is increasingly recognized as an ethical imperative (and not just empirical), further research is necesssary on the principles underlying moral norm in Theory of Planned Behaviour-related behaviour change studies. Second, as organisationlevel changes and related disruptions are regular occurrences in health and social care systems, future implementation interventions need to collect data about the context in which complex interventions are nested and monitor them over time. Analysis of intervention data should include analysis of cross-level linkages between each of the context levels, and between the context and the key evaluation variables [51]. Third, in the design phase of SDM interventions, researchers should plan a prospective process evaluation of the trial to identify barriers and facilitators to implementation that could appear if system- or organisational-level changes occur. Finally, in addition to strategies that address individual-level barriers, research should also focus on identifying and assessing strategies that address organisational and system level barriers.

\section{Conclusion}

From study entry to study exit, the level of healthcare providers' intention to engage in interprofessonal SDM decreased. Moreover, our study results suggested that factors associated with intention changed from study entry to study exit. This finding may be explained by the major restructuring of the health and social care system that took place during the course of the study. Researchers should give more attention to contextual factors and design implementation interventions that can withstand the disruptions of system-level and organisational-level disturbances. 


\section{Supplementary information}

Supplementary information accompanies this paper at https://doi.org/10. 1186/s12913-020-5064-3.

Additional file 1. Constructs of the CPD-Reaction questionnaire. This table presents the five psychosocial constructs of the CPD-Reaction questionnaire with their corresponding items and response choices.

Additional file 2. Intention to engage in IP-SDM among healthcare professionals by discipline at study entry and exit. This table presents median scores of intention by healthcare professionals' discipline at study entry and study exit.

Additional file 3. STROBE checklist for cross-sectional studies. This table presents a checklist of items that should be included in reports of crosssectional studies and how this paper adheres to that checklist.

\section{Abbreviations}

CHU: Centre Hospitalier Universitaire; CRT: Clustered randomised trial; DOLCE: Improving Decision making On Location of Care with the frail Elderly and their caregivers; HSSC: Health and social services centre; IP-

SDM: Interprofessional shared decision-making; NOC: National Occupational Classification; SDM: Shared decision-making

\section{Acknowledgements}

We thank Louisa Blair (CERSSPL-UL, Université Laval, Quebec, Canada) for editing the manuscript.

We also acknowledge the in-kind support of the following local health networks: the Consortium InterESt Santé, the CISSS de la Gaspésie (former CSSS du Rocher Percé) and the CIUSSS de la Capitale Nationale (former CSSS de la Vieille Capitale).

\section{Authors' contributions}

This study was embedded in a parent study led by the Chairholder of the Tier 1 Canada Research Chair in Shared Decision Making and Knowledge Translation. DS, NB, AF, LPR, and FL designed and wrote the parent study. RA designed and wrote this study. FL, DS, NB and LPR sought funding. RA conceived the statistical analysis plan and performed data cleaning. RA performed statistical analyses. RA, FL, JH, and LPR interpreted the data. RA drafted the manuscript. $R A, J H, D S, N B, A F, L P R$, and FL critically reviewed the manuscript for important intellectual content. All authors have read and approved the final version of the manuscript. FL is its guarantor.

\section{Authors' information}

FL is the Chairholder of the Tier 1 Canada Research Chair in Shared Decision Making and Knowledge Translation. JH is an Associate Professor at Université de Lyon. DS is a Full Professor in the School of Nursing and Senior Scientist at the Ottawa Hospital Research Institute. NB is a Manager at the Centre intégré universitaire de santé et de services sociaux (CIUSSS) de la CapitaleNationale. She is also a Research Associate at the Centre de recherche sur les soins et les services de première ligne de I'Université Laval (CERSSPL-UL). AF is a professional scientist in knowledge transfer at the Institut national d'excellence en santé et en services sociaux (INESSS). LPR is a Full Professor at the Department of Mathematics and Statistics of Université Laval. RA has a PhD in Epidemiology from the Department of Social and Preventive Medicine of Université Laval.

\section{Funding}

This research was funded by the Canadian Frailty Network (CFN) and by the Ministère de la Santé et des Services Sociaux (MSSS) du Québec. The funders had no role in the design and conduct of the study; collection, management, analysis, and interpretation of the data; preparation, review, or approval of the manuscript; or the decision to submit the manuscript for publication.

\section{Availability of data and materials}

The datasets used and analysed during the current study are available from the corresponding author on reasonable request.

\section{Ethics approval and consent to participate}

Ethics committee review approval was obtained from the CHU de Québec Multicentre Ethics Committee (MP-CHU-QC-14-001). Written informed consent was obtained from all individual participants included in the study.

\section{Consent for publication}

Not applicable.

\section{Competing interests}

The authors declare that they have no competing interests.

\section{Author details}

${ }^{1}$ Centre de recherche sur les soins et les services de première ligne de I'Université Laval, Quebec, Canada. ${ }^{2}$ Université de Lyon, Université Claude Bernard Lyon 1, Université Saint-Étienne, HESPER EA 7425, F-69008 Lyon, F-42023 Saint-Etienne, France. ${ }^{3}$ Ottawa Hospital Research Institute and Faculty of Health Sciences, University of Ottawa, Ottawa, Canada. ${ }^{4}$ Centre intégré universitaire en santé et services sociaux de la Capitale-Nationale, Quebec, Canada. ${ }^{5}$ Department of Mathematics and Statistics, Université Laval, Quebec, Canada. ${ }^{6}$ Canada Research Chair in Shared Decision Making and Knowledge Translation, 2525, chemin de la Canardière, Quebec G1J 0A4, Canada.

Received: 27 February 2019 Accepted: 28 February 2020

Published online: 12 March 2020

\section{References}

1. Garvelink M, Nganque PA, Adekpedjou R, Diouf NT, Goh L, Blair L, et al. A synthesis of knowledge about caregiver decision making finds gaps in support for those who care for aging loved ones. Health Aff. 2016;35(4): $619-26$

2. Brodaty $H$, Donkin M. Family caregivers of people with dementia. Dialogues Clin Neurosci. 2009:11(2):217-28.

3. Zarit SH, Reever KE, Bach-Peterson J. Relatives of the impaired elderly: correlates of feelings of burden. The Gerontologist. 1980;20(6):649-55.

4. Buckwalter KC, Hall GR. Families of the institutionalized older adult: A neglected resource. In: Aging, health and family: Long term care; 1987. p. 176-96.

5. Williams LA, Moeke-Maxwell T, Wiles J, Black S, Trussardi G, Kerse N, et al. How family caregivers help older relatives navigate statutory services at the end of life: a descriptive qualitative study. Palliat Med. 2018;32(6):1124-32.

6. Adekpedjou R, Stacey D, Briere N, Freitas A, Garvelink MM, Turcotte S, et al. 'Please listen to me': A cross-sectional study of experiences of seniors and their caregivers making housing decisions. PLoS One. 2018;13(8):e0202975.

7. Alzheimer Society of Canada. Prevalence and monetary costs of dementia in Canada. Health Promot Chronic Dis Prev Can. 2016;36(10):231-2.

8. Gilmour H. Unmet home care needs in Canada. Ottawa: Statistics Canada; 2018

9. Legare F, Stacey D, Gagnon S, Dunn S, Pluye P, Frosch D, et al. Validating a conceptual model for an inter-professional approach to shared decision making: a mixed methods study. J Eval Clin Pract. 2011;17(4):554-64.

10. Légaré F, Stacey D, Pouliot S, Gauvin F-P, Desroches S, Kryworuchko J, et al. Interprofessionalism and shared decision-making in primary care: a stepwise approach towards a new model. J Interprof Care. 2011;25(1):18-25.

11. Charles C, Gafni A, Whelan T. Decision-making in the physician-patient encounter: revisiting the shared treatment decision-making model. Soc Sci Med. 1999:49(5):651-61.

12. Reeves S, Pelone F, Harrison R, Goldman J, Zwarenstein M. Interprofessional collaboration to improve professional practice and healthcare outcomes. Cochrane Database Syst Rev. 2017;6:CD000072

13. Tsakitzidis G, Timmermans O, Callewaert N, Verhoeven V, Lopez-Hartmann $M$, Truijen S, et al. Outcome indicators on Interprofessional collaboration interventions for elderly. Int J Integr Care. 2016;16(2):5.

14. Légaré F, Briere N, Stacey D, Bourassa H, Desroches S, Dumont S, et al. Improving decision making on location of care with the frail elderly and their caregivers (the DOLCE study): study protocol for a cluster randomized controlled trial. Trials. 2015;16:50.

15. Adekpedjou R, Stacey D, Brière N, Freitas A Garvelink MM, Dogba MJ, et al. Engaging caregivers in health-related housing decisions for older adults with cognitive impairment: a cluster randomized trial. Gerontologist. 2019 https://doi.org/10.1093/geront/gnz045. 
16. Godin G, Belanger-Gravel A, Eccles M, Grimshaw J. Healthcare professionals' intentions and behaviours: a systematic review of studies based on social cognitive theories. Implement Sci. 2008;3(1):36.

17. Harter M, Moumjid N, Cornuz J, Elwyn G, van der Weijden T. Shared decision making in 2017: International accomplishments in policy, research and implementation. Z Evid Fortbild Qual Gesundheitswes. 2017;123-124:1-5.

18. Couet N, Desroches S, Robitaille H, Vaillancourt H, Leblanc A, Turcotte S, et al. Assessments of the extent to which health-care providers involve patients in decision making: a systematic review of studies using the OPTION instrument. Health Expect. 2015:18(4):542-61.

19. Legare F, Bekker H, Desroches S, Drolet R, Politi MC, Stacey D, et al. How can continuing professional development better promote shared decisionmaking? Implement Sci. 2011;6:68.

20. Michie S, van Stralen MM, West R. The behaviour change wheel: a new method for characterising and designing behaviour change interventions. Implement Sci. 2011;6:42.

21. Davis R, Campbell R, Hildon Z, Hobbs L, Michie S. Theories of behaviour and behaviour change across the social and behavioural sciences: a scoping review. Health Psychol Rev. 2015;9(3):323-44.

22. von Elm E, Altman DG, Egger M, Pocock SJ, Gotzsche PC, Vandenbroucke $J$, et al. The strengthening the reporting of observational studies in epidemiology (STROBE) statement: guidelines for reporting observational studies. Ann Intern Med. 2007;147(8):573-7.

23. Legare F, Borduas F, Freitas A, Jacques A, Godin G, Luconi F, et al. Development of a simple 12-item theory-based instrument to assess the impact of continuing professional development on clinical behavioral intentions. PLoS One. 2014;9(3):e91013.

24. Legare F, Freitas A, Turcotte S, Borduas F, Jacques A, Luconi F, et al. Responsiveness of a simple tool for assessing change in behavioral intention after continuing professional development activities. PLoS One. 2017;12(5):e0176678

25. Government of Canada. Find your National Occupational Classification 2018 Available from: https://www.canada.ca/en/immigration-refugees-citizenship/ services/immigrate-canada/express-entry/eligibility/find-national-occupationcode.html.

26. Maldonado G, Greenland S. Simulation study of confounder-selection strategies. Am J Epidemiol. 1993;138(11):923-36.

27. Kennedy WJ, Bancroft TA. Model building for prediction in regression based upon repeated significance tests. Ann Math Stat. 1971;42(4):1273-84.

28. Derksen S, Keselman HJ. Backward, forward and stepwise automated subset selection algorithms: frequency of obtaining authentic and noise variables. Br J Math Stat Psychol. 1992:45(2):265-82.

29. Ajzen I. The theory of planned behavior. Organ Behav Hum Decis Process. 1991;50(2):179-211.

30. Appleby B, Roskell C, Daly W. What are health professionals' intentions toward using research and products of research in clinical practice? A systematic review and narrative synthesis. Nurs Open. 2016;3(3):125-39.

31. Thompson-Leduc P, Clayman ML, Turcotte S, Legare F. Shared decision-making behaviours in health professionals: a systematic review of studies based on the theory of planned behaviour. Health Expect. 2015;18(5):754-74.

32. Abbasgholizadeh Rahimi S, Lepine J, Croteau J, Robitaille H, Giguere AM Wilson BJ, et al. Psychosocial factors of health Professionals' intention to use a decision aid for Down syndrome screening: cross-sectional quantitative study. J Med Internet Res. 2018;20(4):e114

33. Cote F, Gagnon J, Houme PK, Abdeljelil AB, Gagnon MP. Using the theory of planned behaviour to predict nurses' intention to integrate research evidence into clinical decision-making. J Adv Nurs. 2012;68(10):2289-98.

34. Deschenes SM, Gagnon MP, Legare F, Lapointe A, Turcotte S, Desroches S. Psychosocial factors of dietitians' intentions to adopt shared decision making behaviours: a cross-sectional survey. PLoS One. 2013;8(5):e64523.

35. Gagne C, Harnois I. How to motivate childcare workers to engage preschoolers in physical activity. J Phys Act Health. 2014;11(2):364-74.

36. Godin G, Beaulieu D, Touchette JS, Lambert LD, Dodin S. Intention to encourage complementary and alternative medicine among general practitioners and medical students. Behav Med (Washington, DC). 2007;33(2):67-77.

37. Lavoie M, Godin G, Vezina-Im LA, Blondeau D, Martineau I, Roy L. Psychosocial determinants of physicians' intention to practice euthanasia in palliative care. BMC Med Ethics. 2015;16:6.

38. Lavoie M, Godin G, Vezina-Im LA, Blondeau D, Martineau I, Roy L. Psychosocial determinants of nurses' intention to practise euthanasia in palliative care. Nurs Ethics. 2016;23(1):48-60.
39. Legare F, Godin G, Ringa V, Dodin S, Turcot L, Norton J. Variation in the psychosocial determinants of the intention to prescribe hormone therapy prior to the release of the Women's Health Initiative trial: a survey of general practitioners and gynaecologists in France and Quebec. BMC Med Informatics Decis Making. 2005;5:31.

40. Salzburg Global Seminar. Salzburg statement on shared decision making. BMJ. 2011;342:d1745. https://doi.org/10.1136/bmj.d1745.

41. Elwyn G, Tilburt J, Montori $V$. The ethical imperative for shared decisionmaking. Eur J Pers Cent Healthc. 2013;1(1):129-31.

42. LOI MODIFIANT L'ORGANISATION ET LA GOUVERNANCE DU RÉSEAU DE LA SANTÉ ET DES SERVICES SOCIAUX NOTAMMENT PAR L'ABOLITION DES AGENCES RÉGIONALES Québec, 2015 Updated 2016-04-01. Available from: http://www2.publicationsduquebec.gouv.qc.ca/dynamicSearch/telecharge. php?type=2\&file=/O_7_2/07_2.html.

43. Canada R. Le bilan du PLQ en santé assombri par la réforme Barrette 2018 Available from: https://ici.radio-canada.ca/nouvelle/1112647/bilan-partiliberal-quebec-gaetan-barrette-reforme-sante-plq.

44. Légaré F, Stacey D, Briere N, Fraser K, Desroches S, Dumont S, et al. Healthcare providers' intentions to engage in an interprofessional approach to shared decision-making in home care programs: a mixed methods study. J Interprof Care. 2013;27(3):214-22.

45. Legare F, Ratte S, Gravel K, Graham ID. Barriers and facilitators to implementing shared decision-making in clinical practice: update of a systematic review of health professionals' perceptions. Patient Educ Couns. 2008;73(3):526-35

46. Gaboury I, Lapierre LM, Boon H, Moher D. Interprofessional collaboration within integrative healthcare clinics through the lens of the relationshipcentered care model. J Interprof Care. 2011;25(2):124-30.

47. Lau R, Stevenson F, Ong BN, Dziedzic K, Treweek S, Eldridge S, et al. Achieving change in primary care--causes of the evidence to practice gap: systematic reviews of reviews. Implement Sci. 2016;11:40.

48. Légaré F, Adekpedjou R, Stacey D, Turcotte S, Kryworuchko J, Graham ID, et al. Interventions for increasing the use of shared decision making by healthcare professionals. Cochrane Database Syst Rev. 2018;7:CD006732.

49. Lau R, Stevenson F, Ong BN, Dziedzic K, Treweek S, Eldridge S, et al. Achieving change in primary care--effectiveness of strategies for improving implementation of complex interventions: systematic review of reviews. BMJ Open. 2015;5(12):e009993.

50. Nielsen K, Randall R, Christensen KB. Developing new ways of evaluating organizational-level interventions. Contemp Occup Health Psychol. 2010;1:21-45.

51. Herold DM, Fedor DB, Caldwell SD. Beyond change management: a multilevel investigation of contextual and personal influences on employees' commitment to change. J Appl Psychol. 2007;92(4):942.

\section{Publisher's Note}

Springer Nature remains neutral with regard to jurisdictional claims in published maps and institutional affiliations.

Ready to submit your research? Choose BMC and benefit from:

- fast, convenient online submission

- thorough peer review by experienced researchers in your field

- rapid publication on acceptance

- support for research data, including large and complex data types

- gold Open Access which fosters wider collaboration and increased citations

- maximum visibility for your research: over $100 \mathrm{M}$ website views per year

At $\mathrm{BMC}$, research is always in progress.

Learn more biomedcentral.com/submissions 